\title{
Disease duration in autosomal dominant familial Alzheimer disease
}

\section{A survival analysis}

Ivanna M. Pavisic, MRes, Jennifer M. Nicholas, PhD, Antoinette O'Connor, MRCPI, Helen Rice, MSc, Kirsty Lu, PhD, Nick C. Fox, MD, FMedSci,* and Natalie S. Ryan, MRCP, PhD*

Neurol Genet 2020;6:e507. doi:10.1212/NXG.0000000000000507

\section{Abstract}

\section{Objective}

To use survival modeling to estimate disease duration in autosomal dominant familial Alzheimer disease $(\mathrm{ADAD})$ and ascertain whether factors influencing age at onset also affect survival.

\section{Methods}

Symptomatic mutation carriers (201 presenilin 1 [PSEN1] and 55 amyloid precursor protein $[A P P])$ from $A D A D$ families referred to the Dementia Research Centre, between 1987 and 2019, were included. Survival was assessed with respect to age at onset, year of birth, APOE $\varepsilon 4$ status, cognitive presentation, and sex using multilevel mixed-effects Weibull survival models. The contribution of mutation and family to variance in age at onset and duration was also assessed.

\section{Results}

Estimated mean survival was 11.6 (10.4-12.9) years and was similar for APP and PSEN1 mutations. Sixty-seven percent of the variance in age at onset was explained by mutation and $72 \%$ by mutation and family together. In contrast, only $6 \%$ of the variance in disease duration was explained by mutation specificity and $18 \%$ by family membership. Irrespective of gene, survival appeared longer for successive generations and in individuals with atypical presentations. Older age at onset was associated with longer duration within PSEN1 and shorter duration within APP mutation carriers. No differences in survival time were found between sexes or between mutations located before or beyond codon 200 within PSEN1.

\section{Conclusions}

Survival is influenced by mutation to a much lesser extent than age at onset. Survival time has increased over time and is longer in atypical presentations. These insights may inform the interpretation of disease-modifying therapy trials in $\mathrm{ADAD}$.

\author{
Correspondence \\ Ivanna M. Pavisic \\ ivanna.pavisic.15@ucl.ac.uk
}




\section{Glossary}

$\mathrm{AD}=$ Alzheimer disease $\mathbf{A D A D}=$ autosomal dominant familial Alzheimer disease $\mathbf{A P P}=$ amyloid precursor protein; $\mathbf{C I}=$ confidence interval; ICC $=$ intraclass correlation coefficient; MRC $=$ Medical Research Council; PSEN1 = presenilin 1; TR = time ratio.

There are currently no disease-modifying treatments for Alzheimer disease (AD). Although the search for such treatments continues, it is relevant to investigate variability in disease duration and to study factors influencing survival time. ${ }^{1}$ Autosomal dominant familial Alzheimer disease (ADAD) accounts for less than $1 \%$ of all $\mathrm{AD}$ cases. $^{2}$ Pathogenic mutations in presenilin 1 (PSEN1), ${ }^{3}$ presenilin $2,{ }^{4}$ or amyloid precursor protein $(A P P)^{5}$ are nearly $100 \%$ penetrant, and age at onset is correlated among family members. ${ }^{6}$ This offers a unique opportunity to study survival after symptom onset relatively precisely. Mean age at onset tends to be significantly later for APP than PSEN1 mutations, ${ }^{6}$ and a previous study of our PSEN1 cohort found that $72 \%$ of the variance in age at onset was explained by the specific mutation and $82 \%$ by mutation and family membership together. ${ }^{7}$ As in sporadic $\mathrm{AD}$ (particularly in young-onset $\mathrm{AD}){ }^{8}$ some patients present atypically with initial symptoms involving cognitive domains other than memory (e.g., language or behavior ${ }^{7,9}$ ), which tend to be more common in PSEN1 compared with $A P P$, and particularly in PSEN1 mutations beyond codon $200{ }^{7}$ Given that a considerable amount of the variability in age at onset can be explained by genetic factors, ${ }^{6}$ we undertook the current study to investigate the hypothesis that genetic differences also affect disease duration in ADAD.

Previous studies have often estimated disease length, including only patients who have died, by subtracting an individual's age at onset from their age at death. This leads to an intrinsic bias against longer disease durations as individuals who are affected, but have not yet died, cannot be included. ${ }^{10}$ There have only been a few comprehensive studies of age at onset and disease course in $\mathrm{ADAD}$, including a meta-analysis, ${ }^{6,11,12}$ but none of these used survival models to account for censoring in date of death in those who did not die during the follow-up period. Investigations into generational effects on survival time in $\mathrm{ADAD}$ are also lacking, and survival modeling may offer a useful approach to evaluate these issues.

The current study addresses differences in survival time between APP and PSEN1 mutations, APOE $\& 4$ carriers and $\varepsilon 4$ noncarriers, sexes, cognitive presentations, and PSEN1 mutation position in relation to codon 200 . We also evaluate the extent to which disease duration varies by mutation and family within each gene and the influence of age at onset and year of birth on disease duration. We report these differences in detail while accounting for censoring.

\section{Methods}

\section{Study design and participants}

We conducted a retrospective cohort study of families with histories suggestive of $\mathrm{ADAD}$, which were referred to the Dementia Research Centre at University College London's Institute of Neurology (London, United Kingdom) from clinical and research centers across the United Kingdom and Ireland between July 1, 1987, and September 2, 2019. We used clinical and genetic data from these families (table 1). Inclusion criteria for the study were a family history suggestive of $\mathrm{ADAD}$ and known age at symptom onset. Exclusion criteria were a neurodegenerative condition other than $\mathrm{ADAD}$, unknown age at symptom onset, unknown year of birth, and no information on last year of contact with the center.

\section{Procedures}

Contemporaneous records were evaluated to determine age at onset, defined as the age at which progressive symptoms of cognitive, behavioral, or motor changes were first noticed by someone who knew the patient well, and the nature of the initial symptoms. The cognitive presentation was classified as either amnestic, for those with initial memory symptoms, or atypical, for those with nonamnestic initial symptoms such as behavioral change or symptoms of language or executive dysfunction or dyscalculia. One individual was excluded from the cognitive presentation analysis as they had a motor presentation that preceded cognitive symptoms. Age at death was ascertained from examination of medical records, postmortem reports, and interviews with living relatives and was collected up to September 2019. Disease duration was calculated by subtracting the age at death from the age at onset where this was available $(\mathrm{N}=197)$, and where this was not available, the disease duration at censoring was calculated from the age of the individual at their last assessment $(\mathrm{N}=71)$. One participant with 2 PSEN1 substitutions (p.Thr291Ala and p.Ala343Thr) was excluded from the exon analysis because it was unclear whether pathogenicity was due to one or both of these amino acid substitutions. ${ }^{7}$ Twelve additional individuals were excluded from all analysis: 5 due to uncertainty in year of last contact (information necessary for censoring) and 7 due to unknown year of birth (variable considered as a covariate in all models) (figure e-1, supplementary materials, links.lww.com/ NXG/A312). The intron 4 mutation was classified as involving exon 4 because it is located just outside this exon.

Mutation analysis was performed as described previously ${ }^{7,13}$ using Sanger sequencing. APOE $\varepsilon 4$ status was determined by the Medical Research Council (MRC) Prion Unit (London, United 
Table 1 PSEN1 and APP: characteristics of our cohort $(\mathrm{N}=256)$

\begin{tabular}{|c|c|c|c|}
\hline & $A P P$ & PSEN1 & $A P P+P S E N 1$ \\
\hline No. families & 12 & 64 & 76 \\
\hline No. mutations & 7 & 45 & 52 \\
\hline $\begin{array}{l}\text { Total no. symptomatic } \\
\text { individuals }\end{array}$ & 55 & 201 & 256 \\
\hline Sex (males \%) & 32 (58.2\%) & $94(46.7 \%)$ & $126(49.2 \%)$ \\
\hline No. known deaths & $43(78.2 \%)$ & 147 (73.1\%) & $190(74.2 \%)$ \\
\hline \multicolumn{4}{|l|}{ Clinical presentation } \\
\hline $\begin{array}{l}\text { No. with available } \\
\text { data }\end{array}$ & 37 & 101 & 138 \\
\hline Amnestic & $36(97.3 \%)$ & $83(82.2 \%)$ & $119(86.2 \%)$ \\
\hline Atypical & $1(2.7 \%)$ & $18^{\mathrm{a}}(17.8 \%)$ & $19(13.8 \%)$ \\
\hline \multicolumn{4}{|l|}{ APOE genotype } \\
\hline $\begin{array}{l}\text { No. with available } \\
\text { data }\end{array}$ & 31 & 96 & 127 \\
\hline$A P O E \& 4$ carrier & $7(22.6 \%)$ & $36(37.5 \%)$ & $43(33.9 \%)$ \\
\hline APOE 44 & 1 & 3 & 4 \\
\hline APOE 34 & 6 & 31 & 37 \\
\hline APOE 24 & 0 & 1 & 1 \\
\hline$A P O E \& 4$ noncarrier & $24(77.4 \%)$ & $60(62.5 \%)$ & $84(66.1 \%)$ \\
\hline APOE 23 & 3 & 5 & 8 \\
\hline APOE 33 & 21 & 54 & 75 \\
\hline APOE 22 & 0 & 1 & 1 \\
\hline
\end{tabular}

Abbreviations: $A P P=$ amyloid precursor protein; $P$ SEN1 = presenilin 1. a One additional individual was subsequently excluded as the motor presentation preceded cognitive symptoms.

Kingdom) using minor groove binding probe genotyping assays (TaqMan, Applied Biosystems). As described in our previous work, individuals with novel variants in PSEN1 or APP were assessed for the presence of additional mutations in other dementia-related genes using the MRC Dementia Gene Panel. ${ }^{7,14}$ All novel sequence variants were absent from the Genome Aggregation Database (gnomad.broadinstitute.org/).

In total, 256 individuals were included in the analyses (201 with PSEN1 and 55 with APP mutations) (table-e1, supplementary materials for specific mutations, links.lww.com/NXG/A312).

\section{Statistical analysis}

We investigated differences in disease duration between $A P P$ and PSEN1 genes, APOE $\varepsilon 4$ carriers and $\varepsilon 4$ noncarriers within each genetic group, cognitive presentation, sex, exon number, and position in relation to codon 200 (PSEN1 only) using the Kaplan-Meier survival estimate for descriptive statistics and Weibull multilevel parametric survival analysis (using an accelerated failure time model) to compare the survival function of different groups of patients and test the specific hypothesis. Following the second-order relationship between disease duration and age at onset in Ryman et al. ${ }^{6}$ meta-analysis, we predefined that we would investigate a quadratic term for age at onset. We tested the interaction with gene. Sex, year of birth (range: 1879-1983), and gene were included as fixed effects and family (as a proxy to mutation) as random effects in all survival models. The intraclass correlation coefficient (ICC) was used to quantify the proportion of variance in disease duration explained by mutation and family (supplementary materials, links.lww. com/NXG/A312).

Linear mixed-effects models with random effects for mutation and family and fixed effects for sex, year of birth, and gene were used to compare differences in age at onset between genes and cognitive presentations within PSEN1 mutations.

We used $p<0.05$ as our measure of statistical significance and Stata v14 (StataCorp 2015) or later for all analyses. Bonferroni correction for multiple comparisons was applied for comparison of disease duration between exons.

\section{Standard protocol approvals, registrations, and patient consents}

The study was approved by The National Hospital for Neurology and Neurosurgery and Institute of Neurology Joint Research Ethics Committee (subsequently, National Research Ethics Service Committee, London Queen Square, Research Ethics Committee ref 11/LO/0753). Written informed consent was obtained from all participants or from their consultee if cognitive impairment prohibited written informed consent.

\section{Data availability}

Anonymized data will be shared by request from any qualified investigator.

\section{Results}

Age at symptom onset was available for all 256 individuals included (201 with PSEN1 and 55 with APP mutations). Age at death was available for 190 of those individuals $(77.0 \%$ of the data set: 147 PSEN1 and 43 APP mutations) (table 1).

\section{Disease duration and age at onset: APP vs PSEN1}

Considering only individuals with known age at death (which does not take into account censoring) $(\mathrm{N}=190)$, the mean disease duration was 10.4 years (SD 5.3), range: 2-32 years. Survival analysis $(\mathrm{N}=256)$ revealed a $75 \%$ probability of surviving at least 7 years, $50 \%$ of surviving at least 10 years, $25 \%$ of surviving at least 14 years, and an estimated mean duration of 11.6 (10.4-12.9) years. Estimated survival time was similar between APP and PSEN1 mutation carriers (table 2, figure 1). 
Table 2 Disease duration in our cohort, estimated mean survival time, and effects from survival model comparison

\begin{tabular}{|c|c|c|c|c|c|c|}
\hline & $\begin{array}{l}\text { Disease duration }{ }^{a} \text { : } \\
\text { mean (SD) (y) }\end{array}$ & $\begin{array}{l}\text { Disease duration: } \\
\text { range }(y)^{\mathrm{a}}\end{array}$ & $\begin{array}{l}\text { Estimated survival } \\
(95 \% \mathrm{Cl})(\mathrm{y})^{\mathbf{b}}\end{array}$ & TR & TR: $95 \% \mathrm{Cl}$ & $p$ Value \\
\hline Genes & $N=190$ & & $N=256$ & & & \\
\hline APP & $11.2(4.9)$ & $4-23$ & $12.5(9.7-15.3)$ & Reference & & \\
\hline PSEN1 & $9.7(5.3)$ & $2-32$ & $11.4(10.1-12.7)$ & 0.91 & $0.72-1.17$ & 0.474 \\
\hline Sex & $N=190$ & & $N=256$ & & & \\
\hline Females & $10.0(5.4)$ & $2-32$ & $11.7(10.3-13.1)$ & Reference & & \\
\hline Males & $10.1(5.2)$ & $2-29$ & $11.6(10.1-13.1)$ & 0.99 & $0.86-1.13$ & 0.895 \\
\hline \multicolumn{7}{|l|}{ Clinical presentation } \\
\hline PSEN1 and APP & $N=87$ & & $N=139$ & & & \\
\hline Amnestic & $10.9(5.5)$ & $2-27$ & $11.9(10.6-13.1)$ & Reference & & \\
\hline Atypical & $15.5(7.1)$ & $9-32$ & $17.1(12.4-21.9)$ & 1.44 & $1.08-1.93$ & $0.013^{c}$ \\
\hline PSEN1 & $N=60$ & & $N=102$ & & & \\
\hline Amnestic & $10.2(5.4)$ & $2-27$ & $11.2(9.8-12.6)$ & Reference & & \\
\hline Atypical & $15.9(7.4)$ & $9-32$ & $16.7(12.0-21.5)$ & 1.49 & $1.11-2.01$ & $0.009^{c}$ \\
\hline \multicolumn{7}{|l|}{ APOE status } \\
\hline PSEN1 and APP & $N=92$ & & $N=127$ & & & \\
\hline$\varepsilon 4$ noncarriers & $10.4(5.2)$ & $2-27$ & $11.3(9.9-12.7)$ & Reference & & \\
\hline$\varepsilon 4$ carriers & $12.8(6.4)$ & $5-32$ & $13.2(11.1-15.3)$ & 1.16 & $0.97-1.39$ & 0.100 \\
\hline PSEN1 & $N=69$ & & $N=96$ & & & \\
\hline$\varepsilon 4$ noncarriers & $9.4(4.7)$ & $2-27$ & $10.6(9.0-12.1)$ & Reference & & \\
\hline$\varepsilon 4$ carriers & $12.9(6.7)$ & $5-32$ & $13.2(10.8-15.5)$ & 1.24 & $1.00-1.54$ & $0.046^{c}$ \\
\hline$A P P$ & $N=23$ & & $N=31$ & & & \\
\hline$\varepsilon 4$ noncarriers & $12.7(5.8)$ & $4-23$ & $13.4(10.3-16.6)$ & Reference & & \\
\hline$\varepsilon 4$ carriers & $12.7(5.6)$ & $6-23$ & $12.6(8.4-16.9)$ & 0.94 & $0.65-1.35$ & 0.738 \\
\hline PSEN1: codon 200 & $N=147$ & & $N=201$ & & & \\
\hline Post & $9.9(5.9)$ & $2-32$ & $11.9(9.9-14.0)$ & Reference & & \\
\hline Pre & $9.3(4.7)$ & $3-27$ & $11.5(9.3-13.7)$ & 0.96 & $0.76-1.22$ & 0.746 \\
\hline
\end{tabular}

Abbreviations: $A P P=$ amyloid precursor protein; $\mathrm{Cl}=$ confidence interval; $P S E N 1=$ presenilin $1 ; \mathrm{TR}=$ time ratio.

$\mathrm{TR}, 95 \% \mathrm{Cl}$, and $p$ value encompass the effects of the survival model.

a Disease duration was calculated from individuals with known ages at death only.

${ }^{\mathrm{b}}$ Estimated mean survival included any additional censored data.

'Bold: significant at $p<0.05$.

Considering the cohort as a whole, family membership explained $18 \%$ (ICC $0.18 ; p<0.001$ ) of the variability in disease duration, and mutation specificity explained $6 \%$ (ICC $0.06 ; p=0.188$ ). In patients with a PSEN1 mutation, $25 \%$ of the variance in disease duration was explained by family membership (ICC $0.25, p<0.001$ ) and $10 \%$ by a specific mutation (ICC $0.10, p=0.129$ ). Data were not analyzed separately for APP mutations due to small numbers.

In accordance with our previous work, ${ }^{7}$ age at onset was on average 7.1 years later for individuals with APP mutations (mean age 50.6 years $[\mathrm{SD} 5.6]$, range $38-63$ years) than those with PSEN1 mutations (43.5 years [7.2], range: $30-62$ years; $p<0.001$ ) (figure 1) (figure e-2, links.lww.com/ NXG/A312, for age at onset distribution of sample). In patients with PSEN1 mutations, $72 \%$ of the variance in age at onset was explained by mutation (ICC $0.72, p<0.001$ ). Mutation and family membership together explained $80 \%$ of the variance in age at symptom onset (ICC $0.80, p<0.001$ ). Considering both genes together, $67 \%$ of the variance was explained by mutation and $72 \%$ by mutation and family together. 
A

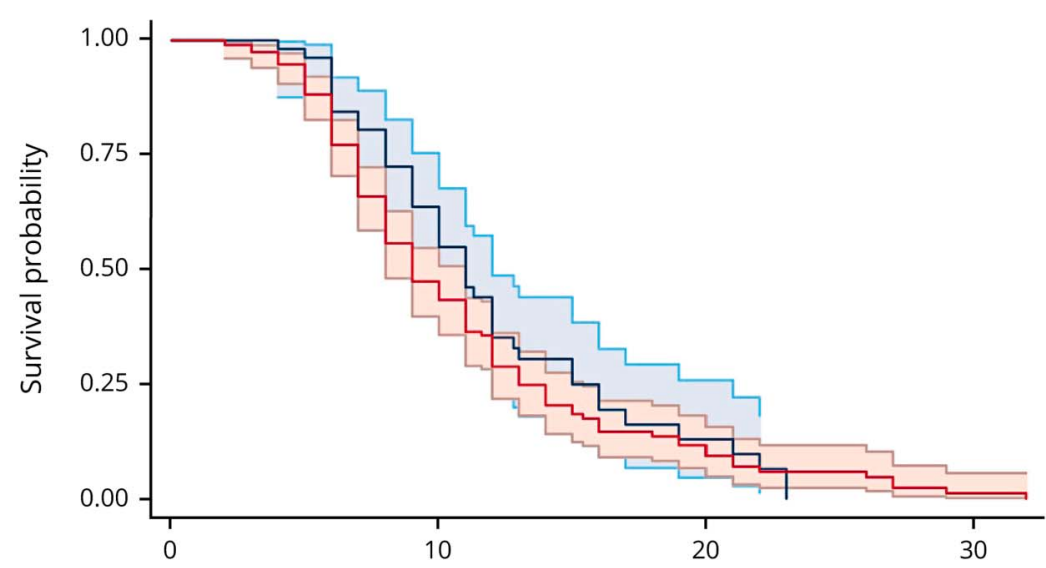

Number at risk

Disease duration (years)
B

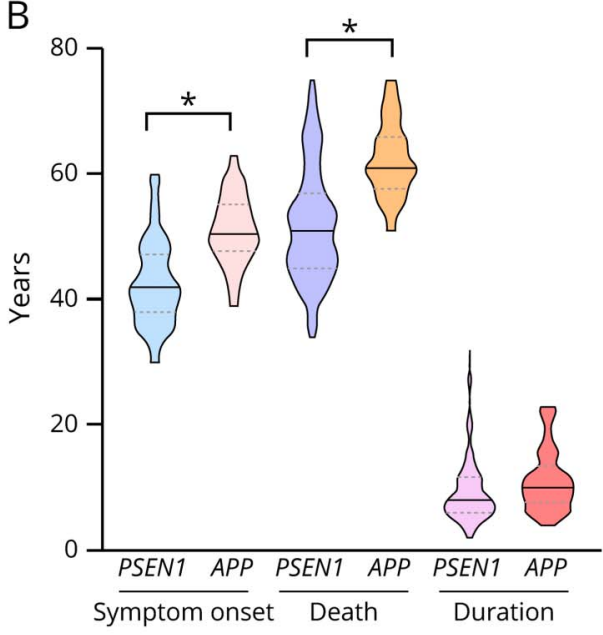

29

70
4

10
0

1

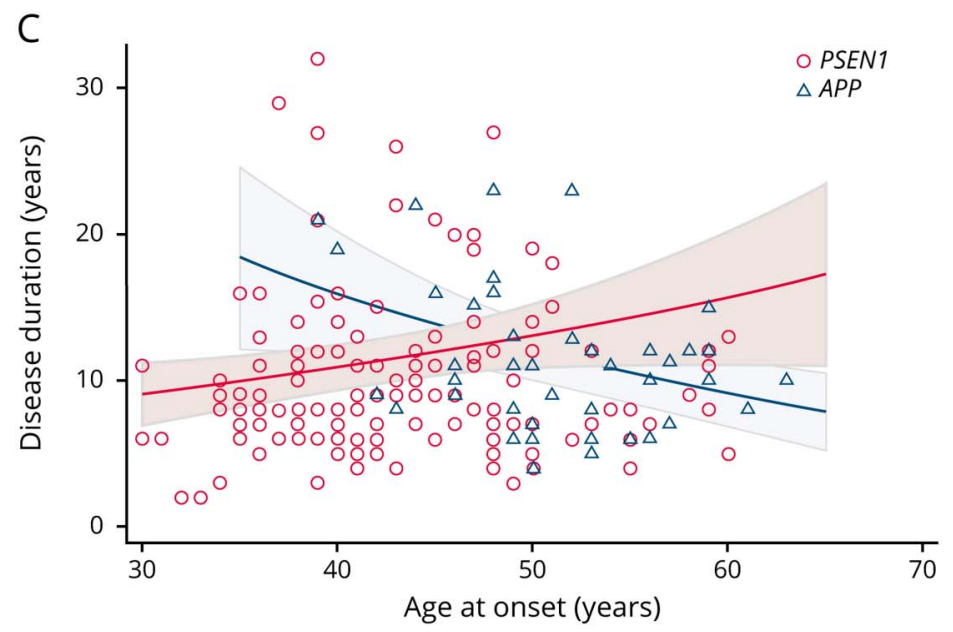

(A) Unadjusted Kaplan-Meier survival plots show the estimated survival probability by disease duration for PSEN1 vS APP. The blue line references APP and the red line PSEN1. Ninety-five percent Cls and number of individuals still alive per disease duration length, by 10 years, by 20 years, and by 30 years, are also shown. (B) Violin plots show the distribution of age at symptom onset, at death, and disease duration for PSEN1 vS APP. Data are median (line) with median interquartile range (upper and lower dotted lines). Age at onset: 42 (38-48) years vs 50 (48-55) years; age at death: 52 (46-58) years vs 61 (58-66) years; and disease duration: 8 (6-12) years vs 10 (8-13) years. "*" indicates significant difference between groups. (C) Scatter plot shows the association between age at symptom onset and age at death in PSEN1 vS APP. The solid line represents the line of best fit from the survival model, adjusted for sex, year of birth, and clustered by family membership for each gene. The shaded area represents $95 \%$ Cls. Markers show the unadjusted raw data: hollow blue triangles represent individuals with APP mutations and hollow red circle markers individuals with PSEN1 mutations. $A P P=$ amyloid precursor protein; $\mathrm{Cl}=$ confidence interval; $P S E N 1=$ presenilin 1 .

Although no linear relationship between an individual's age at onset and the estimated length of disease course was observed \{time ratio $[\mathrm{TR}]=1.00$ (95\% confidence interval $[\mathrm{CI}]$ $0.99-1.01), p=0.286\}$, there was an interaction between age at onset and gene in relation to estimated survival $(\mathrm{TR}=1.05$ [1.02-1.08], $p=0.001)$. In PSEN1 mutations, later ages at onset were associated with longer disease durations (disease duration increased by $1.8 \%$ for every 1 -year increase in age at onset [95\% CI 0.3-3.4]). Whereas in APP, later ages at onset were associated with shorter disease durations (disease duration decreased by $3.0 \%$ for every 1-year increase in age at onset [95\% CI 0.9-4.7]) (figure 1). Like Ryman and colleagues, ${ }^{6}$ we detected an "inverted-U" shape relationship between age at onset and age at death such that patients with early (younger than 40 years) or late (older than 50 years) onset each had shorter disease duration than patients with onset in midlife (40-50 years) irrespective of the gene $\left(\chi^{2}=6.12, p=0.047\right.$; considering age at onset as a quadratic term). However, including the gene interaction abolished this quadratic association $\left(\chi^{2}=1.33, p=0.515\right)$, indicating that gene membership may have driven the "inverted-U" shape effect.

\section{Sex and year of birth}

Sex did not appear to affect disease duration, either for the cohort as a whole (table 2) or for genes separately (data not shown).

Irrespective of the gene, an individuals' year of birth appeared to influence survival and age at onset, with age at onset being 
earlier and duration longer in more recent times. Disease duration increased by 0.6 (95\% CI $0.2-1.0) \%$ for every increase in 1 year of birth $(p=0.003)$. This was also the case when considering genes separately. Further analysis revealed that the greatest difference in survival time was between individuals born before and after 1931: estimated survival: 9.1 (7.7-10.4) years vs $12.2(10.8-13.5)$ years (figure 2$)$. Age at onset decreased by 0.04 (0.01-0.07) years for every increase in 1 year of birth $(p=0.004)$. Comparing individuals born before or after the 1930s, we found that the average age at onset was 45.5 (43.3-47.7) years vs $44.6(42.7-46.5)$ years, respectively (estimated difference $=0.9[-2.1$ to 0.4$]$ years, $p=0.181)$. The significantly longer survival time for later generations remained after adjusting for age at onset $(0.6[0.2-1.0] \%$ increase in survival for every increase in 1 year of birth; survival estimates pre vs post births in the 1930s: 8.9 [7.6-10.3] years vs 12.2 [10.9-13.5] years).

\section{Clinical presentation}

The PSEN1 subgroup with atypical cognitive presentations had, on average, a somewhat older age at onset than those with PSEN1 carriers with amnestic presentations (amnestic: 42.4 years [SD 7.3)] range: 30-62 years vs atypical: 45.4 years [5.7], range: $38-58$ years), but there was little evidence to support this difference, $p=0.592$ ) (figure e-3, supplementary materials, links.lww.com/NXG/A312). Within the PSEN1 group, individuals with atypical presentations had a $49.2 \%$ longer survival time compared with those with amnestic presentations (table 2 and figure 3). Only $8 \%$ of the variance in survival time between individuals with the same cognitive presentations in PSEN1 mutations was explained by family membership (ICC 0.08, $p=$ 0.157). The difference in estimated survival time between cognitive presentations was replicated combining APP and PSEN1 groups together (table 2). We did not find any interactions between the cognitive presentation and codon 200 position, APOE $\varepsilon 4$ status, or age at onset (data not shown). Similar results emerged when we included age at onset as a covariate in the model.

\section{APOE \& 4 status}

$A P O E \varepsilon 4$ status did not have an effect on age at onset in our cohort (mean $[95 \% \mathrm{CI}]: \varepsilon 4$ carriers $=44.0[41.8-46.1]$ years vs $\varepsilon 4$ noncarriers $=44.5[42.5-46.5], p=0.495)$. Considering PSEN1 and APP mutation carriers together, survival analysis $(\mathrm{N}=127)$ revealed similar estimates between $\varepsilon 4$ carriers and $\varepsilon 4$ noncarriers (table 2).

There was no interaction between APOE $\varepsilon 4$ status and gene $(\mathrm{TR}=1.35[0.87-2.08], p=0.180)$. Nonetheless, further analysis revealed an effect seemingly restricted to PSEN1 mutations $(\mathrm{N}=96)$ : there was some evidence that $\varepsilon 4$ carriers had longer survival time compared with $\varepsilon 4$ noncarriers (table 2). $A P O E \& 4$ status did not have an effect on disease duration in the small group of individuals with $A P P$ mutations $(\mathrm{N}=31)$ (table 2) (figure e-5, supplementary materials, links.lww.com/NXG/ $\mathrm{A} 312)$. We then examined APOE $\varepsilon 4$ heterozygous and homozygous groups separately. Because of statistical power
Figure 2 Survival probability pre- and post-births in the 1930s

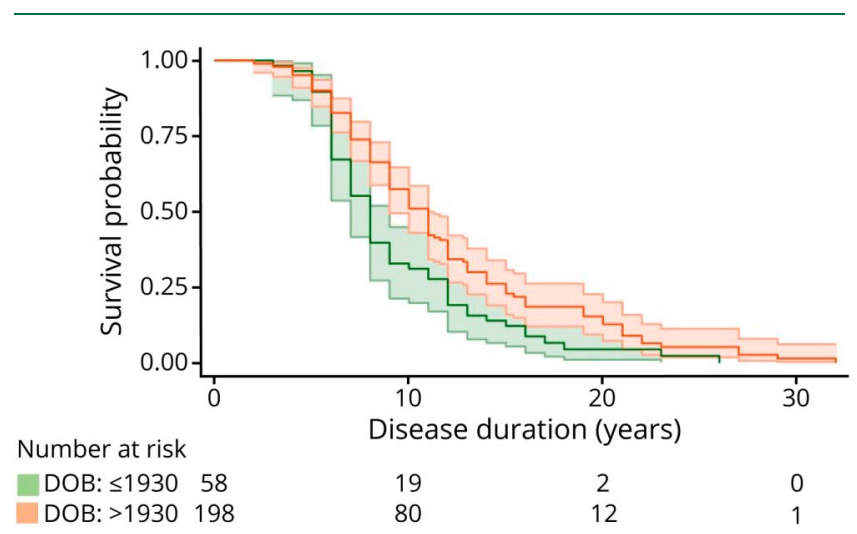

Unadjusted Kaplan-Meier survival plot showing survival by disease duration for individuals born before and after the 1930s. Green references individuals born by 1930 and orange after 1930. Ninety-five percent Cls and number of individuals still alive per disease duration length, by 10 years, by 20 years, and by 30 years, are also shown. $\mathrm{Cl}=$ confidence interval; $\mathrm{DOB}=$ date of birth.

limitations for homozygous carriers $(\mathrm{N}=4)$, we report heterozygous $\varepsilon 4$ carrier results only $(\mathrm{N}=38)$. In the whole cohort, there was a trend toward carriers of $1 \varepsilon 4$ allele having a $20 \%$ longer survival time compared with $\varepsilon 4$ noncarriers (13.7 [11.3-16.0] years vs $11.4[10.0-12.9]$ years, $p=0.056)$. Within the PSEN1 cohort, the possession of $1 \varepsilon 4$ allele was associated with a $30 \%$ longer survival time (13.7 [11.1-16.3] years vs 10.6 [9.0-12.1] years, $p=0.023)$. Comparing carriers of $1 \varepsilon 4$ allele with noncarriers in the $A P P$ cohort did not reveal any differences (12.3 [7.4-17.3] years vs 13.5 [10.1-17.0] years, $p=$ 0.677 ) (figure e-6 and table e-2, supplementary materials, links. lww.com/NXG/A312). Considering age at onset in these models did not change results (data not shown).

Figure 3 PSEN1: survival probability by clinical presentation

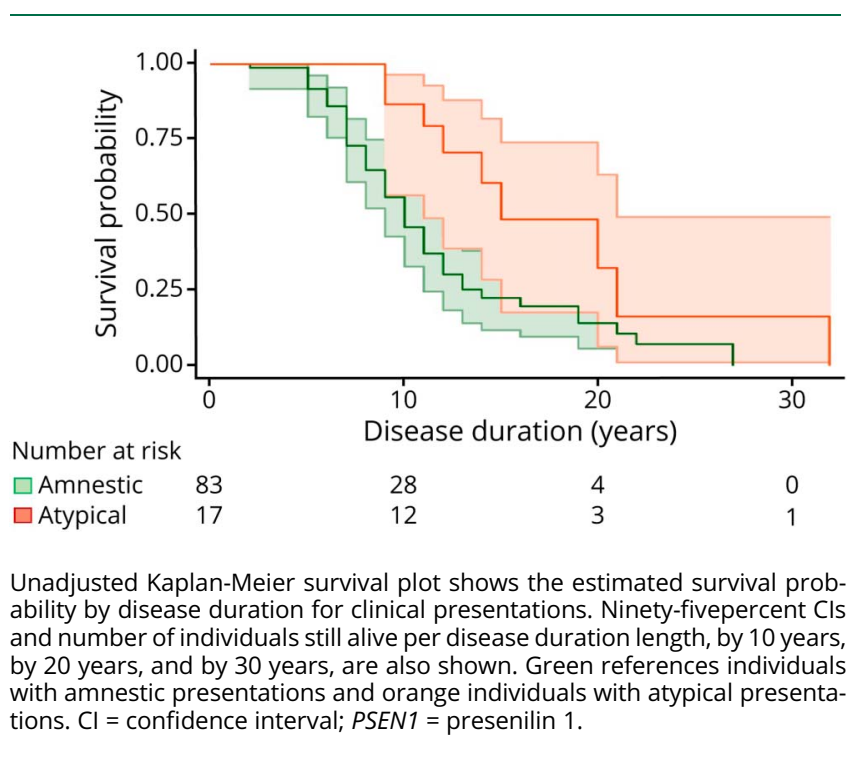




\section{PSEN1 mutation location}

Survival time did not differ between individuals with PSEN1 mutations located pre- or post-codon 200 (table 2). Considering age at onset in these models did not change results (data not shown). Some individuals with PSEN1 mutations in exon $8(\mathrm{~N}=40)$ appeared to reach particularly long disease durations (mean exon 8 duration -in those with known age at death: 11.3 years [SD 5.9], range: 5-32 years; figure e-4, supplementary materials, links.lww.com/NXG/A312). After adjusting for multiple comparisons (28 comparisons: Bonferroni correction), mutations located in exon $8(\mathrm{~N}=58)$ had longer survival estimates than in those in exon $11(\mathrm{~N}=6)$ $(14.0[10.8-17.2]$ years vs $6.2[3.4-9.0]$ years, $p=0.034)$. Fifteen percent of the variability in survival time among those with a mutation on the same exon was explained by family membership (ICC 0.15, $p=0.004$ ).

\section{Discussion}

In this study, individuals with $A P P$ mutations had, on average, similar estimated survival time to individuals with PSEN1 mutations-despite the APP group having an age at onset that was, on average, 7 years later than the average age at onset in the PSEN1 group. Estimated mean survival for our cohort was just over a decade. There was, however, great variability in disease duration for both the PSEN1 (2-32 years) and APP (4-23 years) groups and unlike age at onset, mutation type, and family membership explained relatively little of this variance. In this respect, it may be relevant that we found family membership to account for a slightly larger proportion of variance in disease duration than mutation type, although shared environmental factors could also contribute to this finding. Although longer survival for females compared with males has been reported in sporadic $\mathrm{AD},{ }^{15}$ our results do not provide evidence for sex differences in survival in $\mathrm{ADAD}$, which affects individuals at a much younger age.

In accordance with Ryman et al. ${ }^{6}$ meta-analysis, there was a trend for longer disease duration in individuals with an age at onset of $40-50$ years (compared with $<40$ years or $>50$ years). Looking at PSEN1 and APP mutation carriers separately suggested that while in PSEN1 mutations, later ages at onset were associated with longer disease durations, in APP later ages at onset were associated with shorter disease durations. Although it is unclear why these differences between $A P P$ and PSEN1 exist, different paths of disease course between genes may underly this "inverted-U" shape relationship observed also in other studies. ${ }^{6}$

Our results indicate that individuals born after 1930 had longer survival time compared with those born in previous generations and that age at onset was earlier with more recent years of birth. These suggest that gradually (with no step change), onset or recognition of onset has come earlier. This may likely be due to greater awareness within families, with onset coming about 2 years earlier over the course of 2 generations ( $\sim 50$ years). Nonetheless, survival has increased over and above this. As the difference in age at onset between births before and after 1931 was smaller than the difference in survival time ( 0.9 years vs 3.1 years), this increase in survival time could not solely be explained by earlier awareness of symptoms. The increase in survival observed over the study period accords with the fact that care, as well as life expectancy, has improved. Notably, antibiotics would have become widely available by the time individuals born after the 1930s were clinically affected. ${ }^{16}$

Despite phenotypic and pathologic differences reported between PSEN1 mutations located before and beyond codon $200^{7,17,18}$ we, ${ }^{19}$ like others, ${ }^{17}$ found that disease duration did not significantly differ between these mutation groups. Atypical presentations have been reported to be more common with PSEN1 mutations beyond codon 200 in our cohort, and the prevalence of atypical symptoms also differs markedly between exons, with nonamnestic cognitive presentations and pyramidal signs particularly common with mutations located in exon $8 .^{7}$ Findings from the current study suggest that individuals with exon 8 mutations may also have particularly long disease durations. An intronic polymorphism in PSEN1 between exon 8 and exon 9 has been reported to show a significant association with late-onset disease. ${ }^{20,21}$ There may be differences in the disease process induced by variants located in this region of PSEN1, which drive later ages at symptom onset, longer disease durations, and atypical presentations.

Our findings suggest that carrying APOE $\varepsilon 4$ may be associated with increased survival time in individuals with PSEN1 mutations, but not in APP mutation carriers. However, this would need confirmation as we were not able to demonstrate a significant difference between the 2 genetic groups in the effect of $A P O E \varepsilon 4$. Of interest, the rare APOE $\varepsilon 3$ Christchurch p. Arg136Ser mutation has recently been reported to delay onset of cognitive symptoms by 3 decades in a carrier of the Colombian PSEN1 p.Glu280Ala mutation. ${ }^{22,23}$ These findings could have implications for the role of $A P O E$ in the pathogenesis, treatment, and prevention of $\mathrm{AD}$ and highlight how much remains unknown about the complexities of interactions between different genetic risk factors and their influence on disease onset and survival. Larger ADAD studies that consider the full range of $A P O E$ genotypes and follow individuals over time are needed to untangle the multifaceted effects of the APOE genotype.

Our study has a number of limitations. First, we included individuals born over a range of 100 years. Although this brought the strength of allowing us to study generational effects, it may somewhat limit how much our findings on average disease durations may be generalized to newly diagnosed patients. Although our analysis was adjusted for year of birth, replication in larger cohorts of more recently diagnosed individuals is needed. Second, we were not able to consider the effects of lifestyle (e.g., exercise) or life course (e.g., socioeconomic position) factors on survival. Future 
investigations should study the potential influence of lifestyle elements on survival rates, particularly in light of our finding that genetic factors contribute relatively little to the variance in disease duration we observed in our cohort. This is especially important to better understand the generalizability of our findings to individuals in other $\mathrm{ADAD}$ and sporadic $\mathrm{AD}$ cohorts. Third, cognitive presentations were classified as atypical on the basis that the initial symptoms did not involve memory but instead comprised behavioral change, language impairment, dyscalculia, or executive impairment. Atypical symptoms are often more difficult to recognize as signs of $\mathrm{AD}$, leading to a possible underrepresentation of this group. Nonetheless, it is perhaps noteworthy that the atypical group had a longer disease duration, despite the possibility that symptoms may be noticed later, supporting the notion that there may be biological differences in those with atypical presentations, which underpin both the atypical presentation and the longer disease durations. Last, although we have included a relatively large number of cases, considering the rarity of $\mathrm{ADAD}$, the sample size could be considered a limitation and further investigation of survival in larger $\mathrm{ADAD}$ cohorts will be an important direction for future research.

Multiple factors may contribute to phenotypic variability in $\mathrm{ADAD}$. Characterizing and investigating variability in disease duration is the first step toward allowing patients and their families to plan for the future. A deeper understanding of variability in disease duration and the factors that may influence survival may also inform the interpretation of diseasemodifying trials and potentially even highlight new avenues for targeting the disease.

\section{Acknowledgment}

The authors thank participants and their families for the generous support of this study; their clinical colleagues across the United Kingdom for referring patients; and present and past staff at the Dementia Research Centre for their contribution to their ongoing longitudinal study of familial Alzheimer disease. They are grateful to the MRC Prion Unit at UCL Queen Square Institute of Neurology for performing the genetic analysis.

\section{Study funding}

N.S. Ryan is supported by a University of London Chadburn Academic Clinical Lectureship (548951) and has a clinical research training fellowship (G0 900421) from the Medical Research Council. A. O'Connor is supported by an Alzheimer's Society clinical research training fellowship. N.C. Fox is supported by the Medical Research Council Clinical Senior Fellowship (GO 601846), the NIHR Biomedical Research Centre (540602), and the Medical Research Centre UK Dementia Research Institute Award. The Dementia Research Centre is an ARUK coordinating center and is grateful for support from the MRC Dementias Platform UK and the Rosetrees Trust. The study was undertaken at University College London Hospitals/ University College London that received a proportion of the funding from the Department of Health's NIHR Biomedical
Research Centers funding scheme. This work was supported by the UK Dementia Research Institute, which receives its funding from DRI Ltd, and funded by the UKMedical Research Council, Alzheimer's Society, and Alzheimer's Research UK. The funders of the study had no role in study design, data collection, data analysis, data interpretation, or writing of the report. The corresponding author had full access to the data and had final responsibility for the decision to submit for publication.

\section{Disclosure}

I. M. Pavisic, J.M. Nicholas, A. O'Connor, K. Lu, and N.S. Ryan report no disclosures relevant to this manuscript. H. Rice has previously provided consultancy for Roche. N.C. Fox has provided consultancy for Biogen and Roche, given educational lectures for Eli Lilly and GE Healthcare, and serves on a Data Safety Monitoring Committee for Biogen. Go to Neurology. org/NG for full disclosures.

\section{Publication history}

Received by Neurology: Genetics June 9, 2020. Accepted in final form July 21, 2020.

\section{Appendix Authors}

\begin{tabular}{|c|c|c|}
\hline Name & Location & Contribution \\
\hline $\begin{array}{l}\text { Ivanna M. } \\
\text { Pavisic, } \\
\text { MRes }\end{array}$ & $\begin{array}{l}\text { Department of } \\
\text { Neurodegenerative } \\
\text { Diseases, Dementia } \\
\text { Research Centre, UCL } \\
\text { Queen Square Institute of } \\
\text { Neurology, London, United } \\
\text { Kingdom; UK Dementia } \\
\text { Research Institute at } \\
\text { University College London, } \\
\text { United Kingdom }\end{array}$ & $\begin{array}{l}\text { Conceived the manuscript, } \\
\text { contributed to data } \\
\text { collection, analyzed the } \\
\text { data, and drafted the initial } \\
\text { manuscript }\end{array}$ \\
\hline
\end{tabular}

\begin{tabular}{|c|c|c|}
\hline $\begin{array}{l}\text { Jennifer M. } \\
\text { Nicholas, } \\
\text { PhD }\end{array}$ & $\begin{array}{l}\text { Department of } \\
\text { Neurodegenerative } \\
\text { Diseases, Dementia } \\
\text { Research Centre, UCL } \\
\text { Queen Square Institute of } \\
\text { Neurology, London; } \\
\text { Department of Medial } \\
\text { Statistics, London School of } \\
\text { Hygiene and Tropical } \\
\text { Medicine, United Kingdom }\end{array}$ & $\begin{array}{l}\text { Provided statistical support } \\
\text { and critically revised the } \\
\text { manuscript }\end{array}$ \\
\hline $\begin{array}{l}\text { Antoinette } \\
\text { O'Connor, } \\
\text { MRCPI }\end{array}$ & $\begin{array}{l}\text { Department of } \\
\text { Neurodegenerative } \\
\text { Diseases, Dementia } \\
\text { Research Centre, UCL } \\
\text { Queen Square Institute of } \\
\text { Neurology, London; UK } \\
\text { Dementia Research } \\
\text { Institute at University } \\
\text { College London, United } \\
\text { Kingdom }\end{array}$ & $\begin{array}{l}\text { Recruited participants, } \\
\text { collected clinical data, and } \\
\text { critically revised the } \\
\text { manuscript }\end{array}$ \\
\hline $\begin{array}{l}\text { Helen Rice, } \\
\text { MSc }\end{array}$ & $\begin{array}{l}\text { Department of } \\
\text { Neurodegenerative } \\
\text { Diseases, Dementia } \\
\text { Research Centre, UCL } \\
\text { Queen Square Institute of } \\
\text { Neurology, London; UK } \\
\text { Dementia Research } \\
\text { Institute at University } \\
\text { College London, United } \\
\text { Kingdom }\end{array}$ & $\begin{array}{l}\text { Collected clinical data and } \\
\text { critically revised the } \\
\text { manuscript }\end{array}$ \\
\hline
\end{tabular}


Appendix (continued)

\begin{tabular}{|c|c|c|}
\hline Name & Location & Contribution \\
\hline $\begin{array}{l}\text { Kirsty Lu, } \\
\text { PhD }\end{array}$ & $\begin{array}{l}\text { Department of } \\
\text { Neurodegenerative } \\
\text { Diseases, Dementia } \\
\text { Research Centre, UCL } \\
\text { Queen Square Institute of } \\
\text { Neurology, London, United } \\
\text { Kingdom, University } \\
\text { College London }\end{array}$ & $\begin{array}{l}\text { Provided support for the } \\
\text { interpretation of results } \\
\text { and critically revised the } \\
\text { manuscript }\end{array}$ \\
\hline $\begin{array}{l}\text { Nick C. Fox, } \\
\text { FMedSci }\end{array}$ & $\begin{array}{l}\text { Department of } \\
\text { Neurodegenerative } \\
\text { Diseases, Dementia } \\
\text { Research Centre, UCL } \\
\text { Queen Square Institute of } \\
\text { Neurology, London; UK } \\
\text { Dementia Research } \\
\text { Institute at University } \\
\text { College London, United } \\
\text { Kingdom }\end{array}$ & $\begin{array}{l}\text { Principal investigator of the } \\
\text { study and critically revised } \\
\text { the manuscript }\end{array}$ \\
\hline $\begin{array}{l}\text { Natalie S. } \\
\text { Ryan, } \\
\text { MRCP, PhD }\end{array}$ & $\begin{array}{l}\text { Department of } \\
\text { Neurodegenerative } \\
\text { Diseases, Dementia } \\
\text { Research Centre, UCL } \\
\text { Queen Square Institute of } \\
\text { Neurology, London; UK } \\
\text { Dementia Research } \\
\text { Institute at University } \\
\text { College London, United } \\
\text { Kingdom }\end{array}$ & $\begin{array}{l}\text { Conceived the manuscript, } \\
\text { collected clinical data, and } \\
\text { critically revised the } \\
\text { manuscript }\end{array}$ \\
\hline
\end{tabular}

\section{References}

1. Armstrong R. Factors determining disease duration in Alzheimer's disease: a postmortem study of 103 cases using the Kaplan-Meier estimator and Cox regression. Biomed Res Int 2014;2014:623487.

2. Bekris LM, Yu CE, Bird TD, Tsuang DW. Genetics of Alzheimer disease. J Geriatr Psychiatry Neurol 2010;23:213-227.

3. Sherrington R, Rogaev EI, Liang Y, et al. Cloning of a gene bearing missense mutations in early-onset familial Alzheimer's disease. Nature 1995;375:754-760.

4. Levy-Lahad E, Wasco W, Poorkaj P, et al. Candidate gene for the chromosome 1 familial Alzheimer's disease locus. Science 1995;269:973-977.
5. Goate A, Chartier-Harlin MC, Mullan M, et al. Segregation of a missense mutation in the amyloid precursor protein gene with familial Alzheimer's disease. Nature 1991; 349:704-706.

6. Ryman DC, Acosta-Baena N, Aisen PS, et al. Symptom onset in autosomal dominant Alzheimer disease: a systematic review and meta-analysis. Neurology 2014;83:253-260.

7. Ryan NS, Nicholas JM, Weston PSJ, et al. Clinical phenotype and genetic associations in autosomal dominant familial Alzheimer's disease: a case series. Lancet Neurol 2016; 15:1326-1335.

8. Koedam ELGE, Lauffer V, van der Vlies AE, van der Flier WM, Scheltens P, Pijnenburg YAL. Early-versus late-onset Alzheimer's disease: more than age alone. J Alzheimers Dis JAD 2010;19:1401-1408.

9. Ryan NS, Rossor MN. Correlating familial Alzheimer's disease gene mutations with clinical phenotype. Biomark Med 2010;4:99-112.

10. Kartsonaki C. Survival analysis. Diagn Histopathol 2016;22:263-270.

11. Shea YF, Chu LW, Chan AOK, Ha J, Li Y, Song Y-Q. A systematic review of familial Alzheimer's disease: differences in presentation of clinical features among three mutated genes and potential ethnic differences. J Formos Med Assoc 2016;115:67-75.

12. Canevelli M, Piscopo P, Talarico G, et al. Familial Alzheimer's disease sustained by presenilin 2 mutations: systematic review of literature and genotype-phenotype correlation. Neurosci Biobehav Rev 2014;42:170-179.

13. Janssen JC, Beck JA, Campbell TA, et al. Early onset familial Alzheimer's disease: mutation frequency in 31 families. Neurology 2003;60:235-239.

14. Beck J, Pittman A, Adamson G, et al. Validation of next-generation sequencing technologies in genetic diagnosis of dementia. Neurobiol Aging 2014;35:261-265.

15. Sinforiani E, Citterio A, Zucchella C, et al. Impact of gender differences on the outcome of Alzheimer's disease. Dement Geriatr Cogn Disord 2010;30:147-154.

16. Aminov RI. A brief history of the antibiotic era: lessons learned and challenges for the future. Front Microbiol 2010;1:134.

17. Ringman JM, Monsell S, Ng DW, et al. Neuropathology of autosomal dominant Alzheimer disease in the National Alzheimer Coordinating Center Database. J Neuropathol Exp Neurol 2016;75:284-290.

18. Mann DM, Pickering-Brown SM, Takeuchi A, Iwatsubo T. Members of the Familial Alzheimer's Disease Pathology Study Group. Amyloid angiopathy and variability in amyloid beta deposition is determined by mutation position in presenilin-1-linked Alzheimer's disease. Am J Pathol 2001;158:2165-2175.

19. Ryan NS, Biessels GJ, Kim L, et al. Genetic determinants of white matter hyperintensities and amyloid angiopathy in familial Alzheimer's disease. Neurobiol Aging 2015;36:3140-3151.

20. Hutton M, Hardy J. The presenilins and Alzheimer's disease. Hum Mol Genet 1997;6: 1639-1646.

21. Wragg M, Hutton M, Talbot C. Genetic association between intronic polymorphism in presenilin-1 gene and late-onset Alzheimer's disease. Alzheimer's Disease Collaborative Group. Lancet Lond Engl 1996;347:509-512.

22. Arboleda-Velasquez JF, Lopera F, O'Hare M, et al. Resistance to autosomal dominant Alzheimer's disease in an APOE3 Christchurch homozygote: a case report. Nat Med 2019;25:1680-1683.

23. Acosta-Baena N, Sepulveda-Falla D, Lopera-Gómez CM, et al. Pre-dementia clinical stages in presenilin 1 E280A familial early-onset Alzheimer's disease: a retrospective cohort study. Lancet Neurol 2011;10:213-220. 


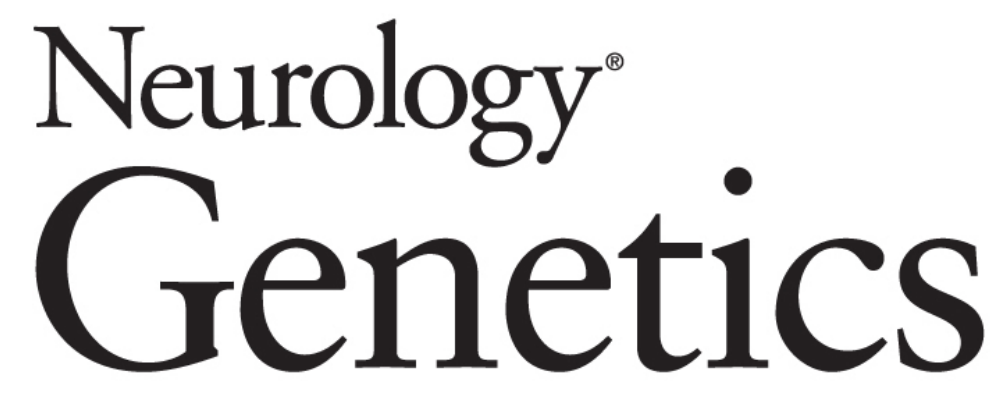

\section{Disease duration in autosomal dominant familial Alzheimer disease: A survival analysis Ivanna M. Pavisic, Jennifer M. Nicholas, Antoinette O'Connor, et al. Neurol Genet 2020;6; \\ DOI 10.1212/NXG.0000000000000507}

This information is current as of August 18, 2020

Updated Information \&
Services
References
Citations
Subspecialty Collections
Permissions \& Licensing
Reprints

Updated Information \&

References

\section{Citations}

\section{Subspecialty Collections}

Reprints including high resolution figures, can be found at: http://ng.neurology.org/content/6/5/e507.full.html

This article cites 23 articles, 1 of which you can access for free at: http://ng.neurology.org/content/6/5/e507.full.html\#\#ref-list-1

This article has been cited by 2 HighWire-hosted articles: http://ng.neurology.org/content/6/5/e507.full.html\#\#otherarticles

This article, along with others on similar topics, appears in the following collection(s):

\section{Alzheimer's disease}

http://ng.neurology.org//cgi/collection/alzheimers_disease

Assessment of cognitive disorders/dementia

http://ng.neurology.org//cgi/collection/assessment_of_cognitive_disord ers_dementia

Information about reproducing this article in parts (figures,tables) or in its entirety can be found online at:

http://ng.neurology.org/misc/about.xhtml\#permissions

Information about ordering reprints can be found online: http://ng.neurology.org/misc/addir.xhtml\#reprintsus

Neurol Genet is an official journal of the American Academy of Neurology. Published since April 2015, it is an open-access, online-only, continuous publication journal. Copyright Copyright @ 2020 The Author(s). Published by Wolters Kluwer Health, Inc. on behalf of the American Academy of Neurology.. All rights reserved. Online ISSN: 2376-7839.

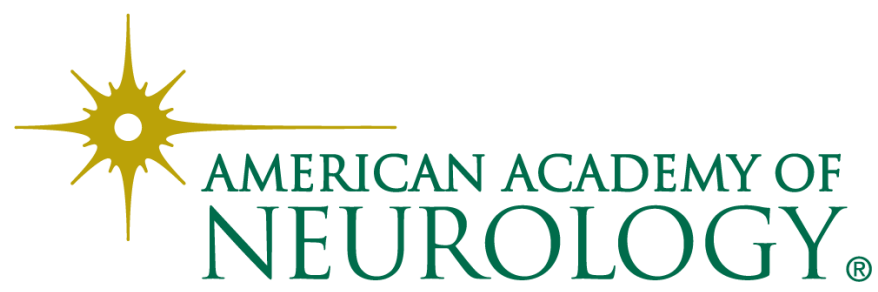

